\title{
COMENTÁRIO AO ARTIGO DE CHRISTINA VITAL DA CUNHA: "IRMÃOS CONTRA O IMPÉRIO: EVANGÉLICOS DE ESQUERDA NAS ELEIÇÓES 2020 NO BRASIL"
}

David Lehmann ${ }^{2}$

Resumo: $\mathrm{O}$ comentário retoma dois temas do artigo de Christina Vital: a laicidade e a questão da família. Pergunta-se se as ideias dos candidatos evangélicos de esquerda têm alguma chance de avançar num público que dificilmente entende porque as igrejas deveriam ficar fora das instituiçóes políticas (laicidade). Também aponta a ausência do tema da família no discurso desses candidatos quando não seria difícil imaginar um enfoque de esquerda sobre os problemas de violência e abandono que sofrem as mulheres e seus filhos nas camadas de baixa renda que conformam a base das igrejas. O comentário parte do pressuposto de que a opiniâo política dominante do público evangélico é conservadora, sobretudo enquanto há questóes que tocam a sexualidade e os direitos reprodutivos, mas o autor reconhece que diante de um universo tão grande e diverso como o evangélico se deve questionar a suposição de que existe uma hegemonia absoluta de ideias conservadoras, apesar das evidências encontradas em pesquisas de opinião.

Palavras-chave: Evangélicos e política; Evangélicos e tolerância; Laicidade; Evangélicos e o Estado.

COMMENT ON CHRISTINA VITAL DA CUNHA: “BROTHERS AGAINST THE

EMPIRE: LEFTIST EVANGELICALS IN THE 2020 ELECTIONS IN BRAZIL”

Abstract: The commentary takes up two themes from Christinas VitaL's article: laïcité and the question of the family. It asks whether the ideas of left-wing evangelical

${ }^{1}$ Como citar: LEHMANN, David. Comentário ao artigo de Christina Vital da Cunha: "Irmãos contra o Império: evangélicos de esquerda nas eleiçóes 2020 no Brasil". Debates do NER, Porto Alegre, ano 21, n. 39, p. 119-126, 2021.

${ }^{2}$ Universidade de Cambridge, Reino Unido. E-mail: adl1@cam.ac.uk. ORCID: https:// orcid.org/0000-0003-4709-0886. 
candidates have any chance of advancing among a public that sees no reason why churches should stay out of political institutions. It also points out the absence of the theme of the family in the discourse of these candidates, when it would not be difficult to imagine a leftist focus on the causes and consequences of the violence and abandonment suffered by women and their children in low-income groups who form the social base of evangelical churches. The commentary assumes that dominant political opinion in the evangelical public is conservative, above all on issues that touch family life, sexuality and reproductive rights. But the author of the commentary recognizes that in the face of a universe as large and varied as the evangelical one, his assumption that there is an absolute hegemony of conservative ideas, largely based on opinion surveys, should be reappraised.

Keywords: Evangelicals and politics; Evangelicals and tolerance; Laïcité; Evangelicals and the state.

$\mathrm{O}$ artigo de Christina Vital nos oferece uma valiosa e bem fundamentada pesquisa sobre uma tendência político-religiosa que muitos poderiam achar extinta. Não é surpreendente que o eleitorado evangélico seja, em sua maioria, conservador, sobretudo nas questóes de costumes, mas a força e a unanimidade evidenciadas nas eleiçóes de 2018 excederam as expectativas. Esse público parece estar encravado numa visão de mundo não só conservadora mas ultraconservadora, e, às vezes, até de paranoia, com traços de intolerância e de desconfiança no confronto com a democracia liberal. Agora, graças a esta pesquisa, vemos que também existe um esforço de levar uma mensagem diferente ao público pentecostal e neopentecostal.

Esses esforços são de grupos de esquerda que procuraram, durante a campanha das eleiçôes municipais de 2020, influenciar o eleitorado evangélico. A diferença entre eles e outros candidatos e lideranças evangélicas mainstream, seus porta-vozes, é a de que parecem ter instrução superior e, às vezes, estudos de teologia. Falam de valores políticos da esquerda contemporânea, de modo parecido ao basismo católico que eu acompanhava nos anos 80 , mas que hoje significa privilegiar os temas de raça, gênero e sexualidade. 
Fiéis a um ecumenismo cristão e à laicidade, evitam adotar uma identidade evangélica excludente, e, com algumas exceçôes, ao ir atrás de votos parecem pouco interessados em lançar mão do estilo pastoral sulfuroso.

Apesar de o público evangélico ser predominantemente negro, feminino e de baixa renda, as mensagens de esquerda prosperaram pouco nessa e em outras campanhas: um número ínfimo de candidatos que aderiram abertamente à causa da esquerda evangélica foi eleito. Isso náo é de se surpreender, segundo uma tese de doutorado, que recebeu o prêmio de melhor tese da ANPOCS 2020, com autoria de Victor Araújo, pessoas de baixa renda relutam em votar em partidos que advogam políticas de redistribuição, e essa tendência se acentua entre os pentecostais (Araújo, 2019). Cabe adicionar, porém, que Araújo toma como suposto que o PT é visto por essas camadas como uma força política com a intenção e a capacidade de implementar tais açóes. Se abstrairmos nossas próprias preferências políticas das análises, lembramos que, numa cultura política clientelista, é possível que os eleitores entendam como redistribuição a alocaçáo de bens concretos (estradas, escolas, creches...) para eles próprios, para seu bairro ou seu grupo profissional, o que, pelo menos em princípio, não é o tipo de redistribuição que o PT representa. Além disso, outros pesquisadores argumentam que pastores evangélicos mostram uma insólita astúcia na gestão do voto ao se organizar ao nível local para maximizar a sua influência a partir da construção de listas eleitorais e, assim, assegurar a eleição de candidatos do seu gosto, organizando, dessa forma, listas fechadas de fato (Rodrigues Silveira e Urizzi Cervi, 2019).

A dificuldade enfrentada por essa esquerda evangélica é a mesma que enfrentavam os padres e as freiras do basismo católico - nos dois casos existe relutância a adotar os simplismos do medo e do pânico: são tendências que prosperam em grupos pequenos e dedicados. O que aconteceu com a Teologia da Libertação foi que seus adeptos e até seus bispos fizeram alianças com o sindicalismo na $\mathrm{ABC}$ e participaram diretamente da fundação do MST no Rio Grande do Sul, daí puderam participar e influenciar o PT no seu período de crescimento. Tiveram apoio material das Pastorais que dependiam da 
$\mathrm{CNBB}$ e das ONGs internacionais, e contaram com uma rede de intelectuais nacionais e internacionais. Montar operaçóes no Facebook ou no Twitter não é suficiente para transformar essa tendência em movimento ou, pelo menos, em algo mais institucionalizado. É necessário apoio externo, seja de igrejas históricas, que sintonizam mais com suas ideias que as pentecostais de maior influência, seja de ONGs internacionais. Aliás, cabe perguntar por que eles não parecem se interessar nessas igrejas.

Um tema importante no texto de Christina Vital é a laicidade. Os evangélicos citados defendem a separação entre religiâo e política, delimitando diferenças entre levar valores religiosos para a esfera política e utilizar o acesso à essa esfera para sustentar interesses de igrejas ou outras instituiçóes religiosas. O abuso da isençáo de impostos é difícil de comprovar, assim como a canalização do dízimo a atividades lucrativas - essas seriam infraçóes fiscais, assim como o abuso do regime de laicidade que protege a isenção das igrejas tanto como ONGs ou entidades sem fins lucrativos. Em tese, a laicidade não permite que as igrejas sejam utilizadas para fazer propaganda eleitoral, mas isso é corriqueiro no Brasil. Os pastores são livres para participar da política, mas só em nome próprio, não em nome de uma igreja e, menos ainda, com recursos da igreja. (Nos EUA essa norma também é frequentemente violada sem punição).

As Igrejas neopentecostais têm, muitas vezes, grandes negócios nas mídias. A mais Edir Macedo já comprou um banco, o qual ele tinha sido sócio minoritário ${ }^{3}$. Existem boatos em torno do destino dos dízimos, que,

${ }^{3}$ Seguinte reportagem da ValorInvest do 2 de julho de 2020 a fatia do Banco Renner que eles ainda não controloava foi comprada por Edir Macedo e sua esposa. Eles foram considerados pelo Banco Central como investidores estrangeiros, por terem domicílio no exterior, e, assim, a compra precisou de um decreto da presidente Dilma Rousseff considerando o investimento como de interesse do governo brasileiro. Em 2018, já no governo Michel Temer, foi editado novo decreto com a possibilidade de a fatia estrangeira no capital ser elevada para até $80 \%$. Na ocasiáo, o colunista Lauro Jardim, de O Globo, publicou que Edir Macedo vinha pressionando o governo para conseguir aumentar sua participaçấo no banco, mas que esbarrava em objeçôes da área técnica do Banco

Debates do NER, Porto Alegre, ano 2I, N. 39, P. i i9-I 26, JAN./Jul. 202 I 
sendo entregues em espécie, não são declarados: por exemplo, se diz que a Universal paga o tempo de programação religiosa da Record com taxas mais altas do comercial, seria ilegal e contrário ao espírito da laicidade que não deve deixar que igrejas se aproveitem da isenção para subvencionar empresas privadas. Já quando se trata de relaçóes de pequenas igrejas com traficantes em bairros periféricos não é possível saber... A própria Christina Vital alude a tal possibilidade no seu livro "Oração de Traficante" (2015), mas trata do tema com discrição.

Faço menção ao tema para aclarar que laicidade não quer dizer que discursos religiosos não devem aparecer na vida política, mas sim que instituiçóes religiosas e suas normas não podem ter um papel em decisóes técnicas ou burocráticas do Estado. Assim por exemplo, admitir que igrejas possam administrar tratamentos espirituais para "curar" o "homossexualismo" (a "cura gay"), ou para recuperar pessoas com dependência química em estabelecimentos religiosos vai contra a laicidade. Entidades filantrópicas apoiadas por igrejas, mas independentes das suas hierarquias, podem.

Os intelectuais evangélicos de esquerda entendem que as normas e as leis não devem se basear no caráter cristão do país, mas para muitos evangélicos isso é uma questão de senso comum. Fazer campanha política para explicar que o Estado deve o mesmo respeito a toda crença, com base na liberdade de crença ou consciência, - incluindo os cultos de matriz africana e a umbanda, por exemplo - é difícil no meio pentecostal, onde o Brasil é tido como um país em que as leis têm de ser regidas pelo etos evangélico ou até pela Bíblia, tal como ela é interpretada por suas autoridades.

Os evangélicos de esquerda citados no trabalho de Christina insistem muito em temas da atualidade em círculos de esquerda como raça, gênero e sexualidade. Eles devem saber que esses temas não são do agrado do público

Central. O banco mudou de nome e agora se chama Banco Digimais. (Disponível em: https://valorinveste.globo.com/mercados/renda-variavel/empresas/noticia/2020/07/02/ edir-macedo-adquire-controle-do-banco-renner-e-pode-alterar-nome.ghtml. Acesso em: 20 jul. 2021). 
pentecostal em geral. Chama minha atenção a ausência do tema da família no seu discurso: claro que esse tema aparece no discurso evangélico como arma de combate contra tudo o que contesta o conformismo nos costumes (a família nuclear tradicional), mas sabemos muito bem que a realidade da vida familiar na América Latina, e não só nas camadas mais pobres, está longe de se conformar com esse ideal. Quem sabe quantas mulheres que pregam a felicidade matrimonial na igreja voltam para casa a fim de educar e alimentar seus filhos sozinhas, ou com a ajuda de parentes (quase sempre mulheres). Às vezes me pergunto como elas lidam com essa "dissonância cognitiva”. O livro de Vital da Cunha descreve uma espécie de "divisão sexual do trabalho" pela qual as mulheres cuidam da vida religiosa e os homens vivem do tráfico, ainda que estes últimos frequentem as igrejas, sobretudo aos cultos de libertação. Pergunto-me se os evangélicos de esquerda se interessam por esse tema, e outros relacionados como a violência doméstica e o abuso sexual.

Também me pergunto se eles estão ansiosos em mostrar que são progressistas, apesar de serem evangélicos. Só a epígrafe dá mostras de ideias propriamente religiosas da esquerda evangélica; para o resto existe a sensação de que são um grupo de pessoas em formação e, provavelmente, de família evangélica que se sentem na defensiva a enfrentar a força avassaladora de discursos moralistas e da espetacularização maniqueísta nas igrejas. Mas eles podem ter uma história no interior do pentecostalismo que, talvez, seja relevante.

Uma pesquisa do Datafolha de 2013 revelou um altíssimo nível de intolerância nas bases pentecostais: $60 \%$ dos aderentes a todas as religióes, e 70\% dos evangélicos, apoiavam a criminalização e até a cadeia para o aborto - mais que entre os parlamentares evangélicos - e eram também favoráveis, na mesma proporção, à diminuição da idade de responsabilidade criminal (Prandi e dos Santos, 2017). As pesquisas da cientista política Amy Erica Smith, combinando dados de uma conferência de pastores em uma pesquisa em profundidade realizada em Juiz de Fora, e outros do Rio 
de Janeiro, acharam fortes indícios de relutância entre evangélicos, até em conceder direitos civis a grupos dos quais discordavam (Smith, 2019, p. 141).

Ainda assim, devemos lembrar que o ex-prefeito evangélico Marcelo Crivella não conseguiu se reeleger em 2020, apesar de o Rio de Janeiro ser uma cidade com maioria evangélica. Seria interessante saber se isso reflete câmbios nas opçôes ideológicas de sua base cristã. Apesar dos resultados desalentadores destas pesquisas para quem valoriza ideais básicas liberais, eu resisto a juntar as dezenas de milhóes de evangélicos de muitas estirpes, num só campo ideológico e por isso mesmo espero que essa esquerda evangélica não perca esperança.

Estando no Brasil durante a campanha de 2018, fiquei com a sensação de viver um momento de pânico, de uma sociedade apressada de paranoia, alimentada pela manipulação muito hábil das redes sociais. Essas condiçóes impossibilitam uma chamada ao bom senso, a olhar as coisas de frente como são, a tratar cada cidadão como um ser racional capaz de entrar numa discussão sobre fatos.

\section{REFERÊNCIAS}

ARAÚJO, Victor Augusto. A religiāo distrai os pobres? Pentecostalismo e voto redistributivo no Brasil. Tese (doutorado em Ciência Política), Universidade de São Paulo, São Paulo, 2019.

PRANDI, Reginaldo; SANTOS, Renan William. Quem tem medo da bancada evangélica? Posições sobre moralidade e política no eleitorado brasileiro, no Congresso Nacional e na Frente Parlamentar Evangélica. Tempo Social 29, n. 2, p. 187-213, 2017.

RODRIGUES-SILVEIRA, Rodrigo; CERVI, Emerson Urizzi. Evangélicos e voto legislativo: diversidade confessional e voto em deputados da bancada evangélica no Brasil. Latin American Research Review 54, p. 560-573, 2019. 
SMITH, Amy Erica. Religion and Brazilian Democracy: mobilizing the People of God. Cambridge Studies in Social Theory, Religion and Politics. Cambridge: Cambridge University Press, 2019.

VITAL DA CUNHA, Christina. Oração de traficante: uma etnografia. Rio de Janeiro: Garamond, 2015.

Recebido em: 05/04/2021

Aprovado em: 05/04/2021 